\title{
Процессы дигитализации как драйвер экономического развития: опыт мировых и российских крупнейших компаний
}

\author{
Елена Андреева, Павел Глухих ${ }^{*}$, Сергей Красных
}

Институт экономики Уральского отделения РАН, г. Екатеринбург, Россия

\author{
Информация о статье \\ Поступила в редакичию: \\ 23.04.2020 \\ Принята \\ к опубликованию: \\ 30.06 .2020 \\ УДК 316.422 .4 \\ JEL F23
}

\section{Ключевые слова:}

крупнейшие компании, цифровизация, глобальный вызов, классификация компаний, рынки будущего, прогнозы технологического развития, стратегии лидерства

\section{Keywords:}

the largest companies, digitalization, Global Challenges, company classification, future market, forecasts of technological development, leadership strategies

\begin{abstract}
Аннотация
Под влиянием быстроменяюшихся технологических условий инструментом конкурентной борьбы становится дигитализация бизнеса. Целью исследования является выявление роли глобальных вызовов как драйвера дигитализаџии и оченка ее вклада в развитие крупнейших публичных компаний мира. На основе теории конкурентоспособности и адаптации разработана модель классификаџии компаний по лидерству и динамике прибыли. Применялся индикативный анализ показателей 946 крупнейших компаний за 2007-2018 г2. Выявлены 4 типа крупнейших компаний, используюшчих стратегии дигитализации, характеризующуие конкурентоспособность, специиализиию, регион.
\end{abstract}

Digitalization Processes As a Driver of Economic Development: Experience of the Global and Russian Largest Companies

Elena Andreeva, Pavel Glukhikh, Sergey Krasnykh

\section{Abstract}

The article focuses on the issue of global technological challenges appearing in companies. The objective of the investigation is to identify the role of global challenges as a source of digitalization, analyze the largest companies as a special form of the digitalization manifestation and assess the contribution of digitalization processes into the development of the global and Russian largest companies. The theories of competitiveness and adaptation are the methodological background. Global business-trends were determined by analyzing the largest companies. To define the corporate strategies of leadership and the digitalization role, the model for the largest companies classification by leadership and profit dynamics was developed.

The indicative analysis of the world largest companies financial and market indicators was used as the research method. The research model was tested on the basis of 964 largest companies indicators, included into the Forbes «Global 2000», within

* Автор для связи: gluchih_p_l@mail.ru

DOI: https://dx.doi.org/10.24866/2311-2271/2020-2/5-23 
the period of 2007-2018. As a result of the study four types of the largest companies with special characteristics (intra-branch competitiveness, companies specialization, region of location) were determined. The digitalization is proved to be the driver of the economic development: the companies strategically using the digitalization of business are or are becoming the market leaders with the above-average profit dynamics. The digitalization affects on the companies competitiveness, and they choose or have to follow one of the following strategies: start to introduce into certain elements of current business processes; expand digitalization, launch additional business models or provide leadership by using digitalization in key business processes.

Not to loose in the competition for the strategically important markets of the future for Russia, it is recommended for domestic companies to develop and implement the tools for regular monitoring of the leading companies digitalization and methods for predicting the translation of the advanced digitalization elements as part of the STI strategy.

\section{Введение}

Драйверами кардинальных экономических изменений в мировой экономике являются следующие глобальные тенденции.

1. Бурное внедрение передовых технологических возможностей, которые приведут к активному изменению в условиях и инструментах ведения бизнеса, в частности: AI / ML (искусственный интеллект, машинное обучение); FinTech (децентрализованные финансовые системы и валюты); Marketplaces (платформы электронной коммерции); Blockchain (ICO, криптовалюты); ІоТ (интернет вещей) и др. Согласно результатам исследования Российской ассоциации электронных коммуникаций и Высшей школы экономики $80 \%$ опрошенных российских экспертов и специалистов утверждают, что уже сейчас в их компаниях применяются технологии искусственного интеллекта. Наиболее популярным типом решений являются виртуальные помощники (применяют 38\% руководителей и ведущих специалистов). Не менее востребован прогнозный анализ (35\%) и машинное обучение (35\%) [1].

2. Формирование технологических рынков будущего. Все ключевые страны мира в глобальной конкуренции делают ставки на приоритеты технологического развития, прикладывая усилия и ресурсы для занятия лидерских позиций. Так, Китай сделал ставку на промышленную робототехнику, автоматизацию, инжиниринг, генную инженерию (их преимущество - этические ограничения других стран). Великобритания - синтетическая биология, инженерия микроорганизмов с искусственно сконструированным геномом. США выбрали нейронауку, новую энергетику и геномику. Германия развивает «индустрию 4.0» (новые принципы организации индустриального производства). Аргентина - роботизацию в сельском хозяйстве. Россия сделала ставку на IT, математику и др. (области, где, как считается, есть квалифицированная рабочая сила и признание). Так, в рамках Национальной технологической инициативы - государственной программы осуществляется поддержка технологических рынков, которые к 2035 г. должны стать основой мировой экономики.

3. Трансформация традиционных рынков в результате платформизации («уберизация» экономики). Применение новых технологий в последние годы позволило приступить к решению многих задач, которые ранее были не решаемыми. Объем таких доступных задач трудно оценить, меняются одновременно и бизнес-процессы [2] и поведение людей. Приведем лишь несколько 
примеров, когда технологии привели к появлению новых рынков - мобильный интернет, социальные сети и т.д. Платформа как модель организации бизнеса создает дополнительные возможности для быстрого внедрения новых технологий, создавая преимущества для нескольких групп участников, включая и ее организатора. Платформа выступает сервисом, позволяющим объединить интересы покупателей и продавцов, чтобы с минимальными издержками обмениваться товарами, услугами и информацией. Примером такой платформы является компания еВау - крупнейший мировой интернетсервис (более 30 стран), позволяющий продавцам размещать свои товары и услуги в формате интернет-магазина и/или аукциона, а покупателям приобретать. Так, по всему миру начал формироваться рынок электронных сервисов объявлений. Другим видом платформ являются целые экосистемы, созданные компаниями Apple и Google в виде магазинов мобильных приложений для смартфонов на базе соответственно операционных систем iOS и Android. B этих платформах также есть две группы участников - потребители (покупатели) приложений и их разработчики. Созданный мировой рынок мобильных приложений продолжает расти, так согласно данным компаний в 2018 г. в Google Play и App Store было осуществлено 113 млрд загрузок приложений на сумму 76 млрд долл. США [3]. Еще более показательным оказался пример компании Uber, которая на традиционном рынке такси сделала интернетсервис, напрямую связывающий пассажиров и водителей. Таким образом, существующий рынок вынужден был сильно трансформироваться, многим классическим компаниям-перевозчикам пришлось также переходить на бизнес-модель платформы. Очень вероятно, что данная тенденция продолжится - и в других существующих отраслях будут появляться платформы, забирающие потребителей у текущих компаний.

Российские компании также включились в данный тренд и внедряют бизнес-модель платформы. Существующие российские интернет-платформы, представлены в различных сферах:

1) интернет-сервисы объявлений (Авито, Юла и др.);

2) маркетплейсы (агрегатор магазинов) - интернет-площадки, которые помогают продавцам и покупателям находить друг друга онлайн и приобретать необходимые товары, услуги и информацию. Маркетплейсы можно поделить на такие тематические категории:

- товары, продукты (широкого назначения: Яндекс.Маркет, Ozon, «Беру» и др.; специализированные: одежда и обувь (Lamoda и др.) и т.д.;

- услуги, сервисы: такси (Яндекс.Такси, RuTaxi («Везет», «Лидер»), Fasten («Такси Сатурн», RedTaxi)) и т.д.;

- информация, инвестиции и краудфандинг: банковские и инвестиционные услуги (Банки.ру, Сравни.ру и др.); краудфандинг (сервисы сбора инвестиции для проектов: Planeta.ru, Boomstarter.ru и др.).

Под влиянием данных глобальных трендов в быстроменяющихся технологических условиях все важнее становится бизнес задача - максимально быстро захватить рынок [4], пока копирующие продукт конкуренты находятся в состоянии догоняющих. Эксперты институтов развития, в частности руководитель акселератора Фонда развития интернет инициатив - Дмитрий Калаев подчеркивают специфику отечественного бизнеса, что российские пред- 
приниматели справляются с тем, чтобы лучше других придумать какой-то новый продукт [5]. Но они часто не обладают компетенцией быстро занять лидирующую позицию на рынке. Основными причинами отсутствия данной компетенции, по мнению эксперта, является менталитет и не достаточное понимание того, что в современной глобальной экономике из-за увеличения темпов дигитализации конкурентные преимущества достигаются и теряются на порядок быстрее, чем ранее. Так называемое «окно возможностей» сохраняется всего несколько лет. Если им своевременно не воспользоваться и не приступить к экспансии зарубежных рынков, то через некоторое время бизнес не только ощутит «потолок роста» на локальном рынке, но и совсем может исчезнуть, не набрав критической массы потребителей.

Поэтому целью данного исследования является выявление роли глобальных вызовов как движущей силы дигитализации крупнейших публичных компаний мира, определение ее форм проявления и оценка вклада процессов дигитализации в развитие мировых и российских крупнейших компаний. Для ее достижения предполагается реализовать следующие задачи исследования: выявить роль глобальных вызовов в дигитализации экономики; выявить глобальные тенденции для выявления участия крупнейших компаний в дигитализации бизнеса; разработать и апробировать модель их классификации, универсальную для различных отраслей по лидерству и динамике прибыли для выявления роли корпоративных стратегий в развитии дигитализации.

Чтобы быть готовым к конкуренции не только в России, но и к экспансии на мировой рынок нужно знать перспективные направления дигитализации, причины и условия их появления.

\section{Глобальные вызовы как источник дигитализации экономики}

Исходный термин «вызов» прочно вошел в научный оборот с момента его введения британским историком и философом Арнольдом Тойнби [6] в виде закона «вызова и ответа», когда природные факторы или историческая ситуация формируют перед обществом проблему («вызов»), ограничивающую дальнейшее развитие и требующее поиска варианта решения («ответа»).

Проведенный авторами анализ сущности «Global Challenges» позволил выявить основные подходы к этому явлению (табл. 1).

Представляется, что понимание термина «Global Challenges» должно включать три обязательные составляющие: 1) «мегатенденции» могут иметь как природное, так и технологическое происхождение; 2) носят глобальный характер, решение затрагивает субъектов из различных стран мира; 3) субъекты, предпринявшие своевременные меры получают конкурентные преимущества.

Всеохватывающий характер происходящих изменений не оставляет безучастными экономических агентов. Они не только ощущают воздействие дигитализации, но стремятся управлять данными процессами. В статье под управлением процессами дигитализации понимается целенаправленное воздействие государства и/или компаний на факторы внутренние и внешние среды для повышения собственных конкурентных преимуществ путем формирования и развития лидирующего положения на мировых рынках посредством цифровизации хозяйственных процессов. 
Tеоретические подходы к сущности «Global Challenges»

\begin{tabular}{|c|c|c|}
\hline Сущность определения & Автор(ы) & Основные отличия \\
\hline $\begin{array}{l}\text { Global Challenges - потенциальные кризисы, } \\
\text { которые требуют коллективных действий, моти- } \\
\text { вированных на благо мирового сообщества }\end{array}$ & $\begin{array}{l}\text { Сандлер Т. } \\
(1997 \text { г.) [7] }\end{array}$ & $\begin{array}{l}\text { Автор рассматривает дан- } \\
\text { ное определение в контек- } \\
\text { сте решения глобальных } \\
\text { проблем, которые благо- } \\
\text { приятно повлияют на ми- } \\
\text { ровое сообщество }\end{array}$ \\
\hline $\begin{array}{l}\text { Global Challenges - изменение климата, нехватка } \\
\text { воды, исчезновение рыболовства, финансовая } \\
\text { нестабильность, волны мигрантов и беженцев, } \\
\text { терроризм, сильная и непреодолимая нищета - } \\
\text { все это примеры глобальных проблем, решение } \\
\text { которых требует сотрудничества между странами }\end{array}$ & $\begin{array}{l}\text { Бхаргава В. } \\
(2006 \text { г.) [8] }\end{array}$ & $\begin{array}{l}\text { Главная черта данного } \\
\text { определения заключается в } \\
\text { совместном решении гло- } \\
\text { бальных проблем, путем } \\
\begin{array}{ll}\text { сотрудничества между } \\
\text { странами }\end{array} \\
\end{array}$ \\
\hline $\begin{array}{l}\text { Global Challenges - предвидеть эволюцию про- } \\
\text { блем, обусловленных различными политически- } \\
\text { ми, экономическими, правовыми, демографич- } \\
\text { скими, экологическими и технологическими } \\
\text { факторами, сложная задача, ясно, что их отдель- } \\
\text { ные и совокупные воздействия уже формируются } \\
\text { и будут продолжать формировать международ- } \\
\text { ную гуманитарную деятельность }\end{array}$ & $\begin{array}{l}\text { Гелсдорф К. } \\
(2010 \text { г.) [9] }\end{array}$ & $\begin{array}{l}\text { Данное определение рас- } \\
\text { сматривается со стороны } \\
\text { формирования междуна- } \\
\text { родной гуманитарной } \\
\text { деятельности }\end{array}$ \\
\hline $\begin{array}{l}\text { Global Challenges - набор «мегатенденций», таких } \\
\text { как изменение демографических характеристик, } \\
\text { изменение экономической и социальной динами- } \\
\text { ки, прогресс в области технологий и тенденции к } \\
\text { ухудшению состояния окружающей среды }\end{array}$ & $\begin{array}{l}\text { ООН, Департа- } \\
\text { мент по эконо- } \\
\text { мическим и } \\
\text { социальным } \\
\text { вопросам } \\
(2013 \text { г.) }[10] \\
\end{array}$ & \begin{tabular}{|l} 
Глобальные вызовы - как \\
набор «мегатенденций»
\end{tabular} \\
\hline $\begin{array}{l}\text { Global Challenges - каждый вызов современной } \\
\text { жизни, такие как обеспечение энергетики, здоро- } \\
\text { вья, продовольственного питания в устойчивом } \\
\text { мире с прогнозируемыми девятью миллиардами } \\
\text { жителей, который имеет сложные научные и } \\
\text { технологические компоненты и носит глобаль- } \\
\text { ный характер, даже несмотря на то, что его вы- } \\
\text { ражение часто включает в себя национальные } \\
\text { особенности }\end{array}$ & $\begin{array}{l}\text { Шарп П., } \\
\text { Лешнер А. } \\
(2014 \text { г.) [11] }\end{array}$ & $\begin{array}{l}\text { По мнению авторов, гло- } \\
\text { бальные вызовы часто } \\
\text { включают в себя нацио- } \\
\text { нальные особенности }\end{array}$ \\
\hline $\begin{array}{l}\text { Global Challenges - стоящие перед человечеством } \\
\text { глобальные вызовы, формирующие пространство } \\
\text { для инновационной деятельности и определяю- } \\
\text { щие ниши для глобальных прорывных техноло- } \\
\text { гических проектов }\end{array}$ & $\begin{array}{l}\text { Открытый } \\
\text { университет } \\
\text { Сколково } \\
\text { (2015 г.) [12] }\end{array}$ & $\begin{array}{l}\text { Для решения вызовов } \\
\text { необходимо правильно } \\
\text { определить ниши глобаль- } \\
\text { ных прорывных техноло- } \\
\text { гических проектов } \\
\end{array}$ \\
\hline
\end{tabular}

Источник: составлено автором

\section{Реакция ведущих стран и крупнейших компаний на вызовы цифровизации}

На различных управленческих уровнях предпринимаются попытки предвосхищения и положительного использования результатов дигитализации в условиях технологической трансформации. В качестве ответа на технологические вызовы, ведущие страны мира разработали и реализовывали в последние годы соответствующие программные документы и стратегии, представленные в табл. 2. 
Таблийа 2

Официальные прогнозы технологического развития ведуцих стран

\begin{tabular}{|c|c|c|}
\hline Страна & Название прогноза, годы & Основные отличия \\
\hline КНP & $\begin{array}{l}\text { Государственная програм- } \\
\text { ма долгосрочного и средне- } \\
\text { срочного развития науки и } \\
\text { техники на 2006-2020 г. } \\
\text { [13] }\end{array}$ & $\begin{array}{l}\text { Строится на уникальном сочетании использования } \\
\text { передового мирового опыта и сильной государствен- } \\
\text { ной поддержке с финансированием ключевых вузов, } \\
\text { попытке интеграции НИИ с бизнесом, усиление под- } \\
\text { держки успешных учёных и научных коллективов } \\
\text { через грантовые фонды, переход на эффективные } \\
\text { контракты и т.д. [14, с. 16] }\end{array}$ \\
\hline Россия & $\begin{array}{l}\text { Прогноз } \\
\text { технологического развития } \\
\text { Российской Федерации на } \\
\text { период до } 2030 \text { года } \\
\text { (2014-2030 гг.) [15] }\end{array}$ & $\begin{array}{l}\text { В прогнозе указываются наиболее перспективные } \\
\text { области развития науки и технологий, которые могут } \\
\text { обеспечить реализацию конкурентных преимуществ } \\
\text { страны. По } 7 \text { приоритетным направлениям приводятся } \\
\text { вызовы и окна возможностей, в том числе для России, } \\
\text { определены потенциальные будущие инновационные } \\
\text { рынки и перспективные группы продуктов и услуг, } \\
\text { указаны темы перспективных научных исследований }\end{array}$ \\
\hline Франция & $\begin{array}{l}\text { Национальная } \quad \text { стратегия } \\
\text { исследований } \text { Франция }- \\
\text { Европа } 2020 . \\
\text { (2014-2020 гг.) [16] } \\
\end{array}$ & $\begin{array}{l}\text { Стратегия сводится к системе приоритетных направле- } \\
\text { ний исследований, их перевод в разработку с целью } \\
\text { коммерциализации результатов исследований } \\
{[17, \text { с. } 355]}\end{array}$ \\
\hline США & $\begin{array}{l}\text { Стратегия американских } \\
\text { инноваций (2015-2030 гг.) } \\
{[18]}\end{array}$ & $\begin{array}{l}\text { Основная нацеленность стратегии направлена на ре- } \\
\text { шение вопросов инновационной модернизации страны } \\
\text { с ориентацией на мировое технологическое лидерство }\end{array}$ \\
\hline $\begin{array}{l}\text { Южная } \\
\text { Корея }\end{array}$ & $\begin{array}{l}\text { Долгосрочный } \\
\text { развития науки и техноло- } \\
\text { гий до } 2025 \text { г. } \\
\text { (1999-2025 гг.) [19] }\end{array}$ & $\begin{array}{l}\text { Корея позиционирует себя как один из ответственных } \\
\text { членов мирового сообщества, которая готова играть } \\
\text { активную роль в международных усилиях по улучше- } \\
\text { нию благосостояния людей посредством развития } \\
\text { науки и техники }\end{array}$ \\
\hline Япония & $\begin{array}{l}\text { Пятилетний план } \text { научно- } \\
\text { технического } \\
\text { Японии (2016-2020 гг.) [20] }\end{array}$ & $\begin{array}{l}\text { Детализированный план для деятельности государст- } \\
\text { венных ведомств по решению двух «суперзадач»: } \\
\text { 1) «взаимоувязанный рост и развитие человеческих, } \\
\text { интеллектуальных и финансовых ресурсов» и 2) фор- } \\
\text { мирование «суперинтеллектуального общества» в } \\
\text { Японии [21] }\end{array}$ \\
\hline
\end{tabular}

Источник: составлено автором

Рассмотренные документы являются стратегиями ведущих стран в осуществлении глобальной технологической трансформации, то есть по сути выступают ответом на вызовы именно дигитализации, в том числе путем удовлетворения социальных потребностей и гармонизации человеческой деятельности и природы, как, например, в Южной Корее и Франции. Также стоит отметить высокую ориентацию на коммерциализацию результатов исследований во Франции. В Японии программа направлена на формирование «суперинтеллектуального общества». В российском Прогнозе научнотехнологического развития РФ до 2030 г. основной задачей является ответ на вызовы и на основные окна возможностей по приоритетным направлениям развития науки, технологии и техники.

Также попытки управления процессами дигитализации предпринимаются на корпоративном уровне. Методологической основой такого управления выступают теории конкурентоспособности и адаптации. Как яркий пред- 
ставитель теории конкурентоспособности Майкл Портер [22] доказывал, что компания создает преимущества, организуя стратегическую деятельность по проектированию, производству и маркетингу товаров и услуг с лучшим качеством и/или меньшими издержками, чем конкуренты.

Импульсом к активному использованию теории адаптации в экономических исследованиях стали задачи инновационного развития компаний. Так, если в 2000-е гг. доминирующим источником адаптации компаний была глобализация, в 2007-2010-е гг. - мировой экономический кризис, то в 2010-е годы - глобальные вызовы, в том числе обусловленные дигитализацией (Н.П. Кузнецова, К.Е. Лещенко, Н.А. Ломагин [23]; А.С. Стецюкевич [24]; H.S. Park [25]; Т. Zhang [26]; Р. Hoontrakul [27]; В.И. Окунев [28] и др.).

Основные положения теории адаптации применительно к компаниям можно сформулировать следующим образом:

- основная цель адаптации: сохранение или улучшение позиции компании на рынке;

- базовая причина адаптации: угрозы от меняющихся факторов внешней среды;

- ключевой инструмент адаптации: изменение факторов внутренней среды.

Таким образом, теории конкурентоспособности и адаптации выступают основой для успешного использования компаниями окон возможностей и нивелирования угроз от глобальных вызовов. Готовность и способность к адаптации напрямую зависит от типа компаний.

Для выявления глобальных тенденции авторами были проанализированы крупнейшие публичные компании мира с учетом их отраслевой специализации, за период с 2007 по 2018 гг. На основе анализа данных рейтинга Forbes «Global 2000» [29] - крупнейших компаний мира были выделены следующие глобальные тенденции.

Главенствующую роль на мировом рынке в последние годы занимают крупнейшие компании - представители банковского сектора (в 2018 г. 7 из 10 крупнейшие банки; в 2013 г. - 5; в 2007 г. - 3). Среди первых десяти в рейтинге «Global 2000», лидирующих по комплексу основных показателей (объем продаж, прибыль, величина активов, рыночная стоимость компании), 9 являются представителями финансового сектора, в том числе 7 банков (4 китайских, включая крупнейший в мире по активам ICBC и 3 американских, из них JPMorgan Chase c наибольшей рыночной капитализацией в банковском сектоpe), а также инвестиционным холдингом Уоррена Баффета Berkshire Hathaway и китайской страховой группы компаний Ping An Insurance. Одна из этой первой десятки - компания, представляющая сферу IT - Apple, которая является не только лидером компьютерного оборудования и программного обеспечения, но и опередила все другие сектора, включая нефтяной и финансовый по объему прибыли и рыночной капитализации (в 2018 г. 1-е место среди всех мировых компаний из всех секторов экономики). При этом Apple занимало 8-е место по объему продаж, 100-е место по объему активов.

Одновременно с этим за период с 2007 по 2018 гг. уменьшается количество западных крупнейших компаний, и увеличивается число азиатских. В 2007 году по данному показателю с большим преимуществом доминиро- 
вали США (659 компаний), практически в два раза по данному показателю от лидера отставала Япония (291), на третьем месте была Великобритания (123) (рис. 1).

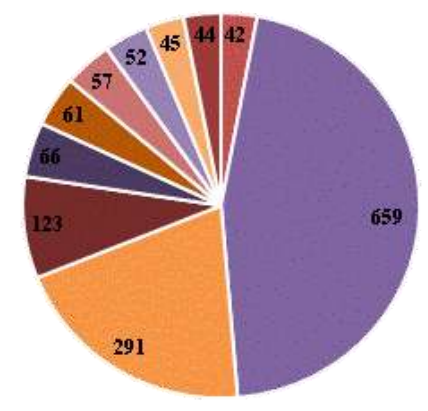

\begin{tabular}{|c|c|c|c|}
\hline - Тайвань & $\square$ ФША & 国Япония & - Велпккобританкя - Ф раншия \\
\hline - Канада & - Германкя & ఐ Южная Корея & 回 Гонконт \\
\hline
\end{tabular}

Puc. 1. Топ-10 стран с наибольшим количеством крупнейших компаний по версии «Forbes» в 2007 г.

Источник: составлено авторами по [29]

За последние 11 лет огромный скачок совершил Китай, увеличив количество крупнейших публичных компаний более чем в 5 раз $(+190)$ - заняв 2-е место после США (сократилось на 103). Также значительно выросло количество компаний в списке Global 2000 из Индии и Южной Кореи (рис. 2).
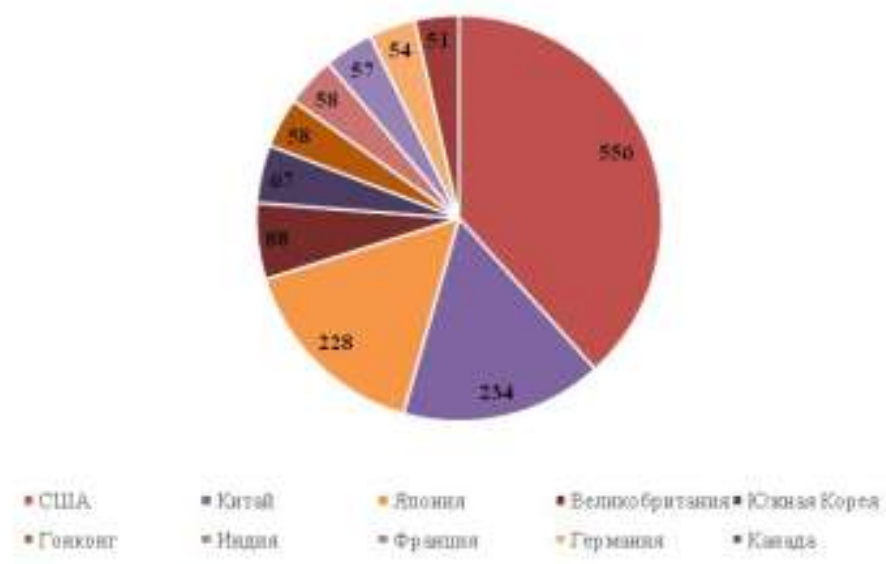

Puc. 2. Топ-10 стран с наибольшим количеством крупнейших компаний по версии «Forbes» в 2018 г.

Источник: составлено авторами по [29]

Основными причинами такого перераспределения стали рост стабильности деловой среды в азиатском регионе, дешевая рабочая сила и благоприятная инвестиционная обстановка. 
Если рассматривать динамику продаж, то наибольший рост за период с 2007 по 2018 гг. как раз приходится на отрасли, связанные с цифровой сферой. Доминирующие отрасли по индексу продаж: интернет и сетевая торговля (более чем в 10 раз) компьютерное оборудование, медицинские услуги, биотехнологии (более чем в 3 раза) (рис. 3).

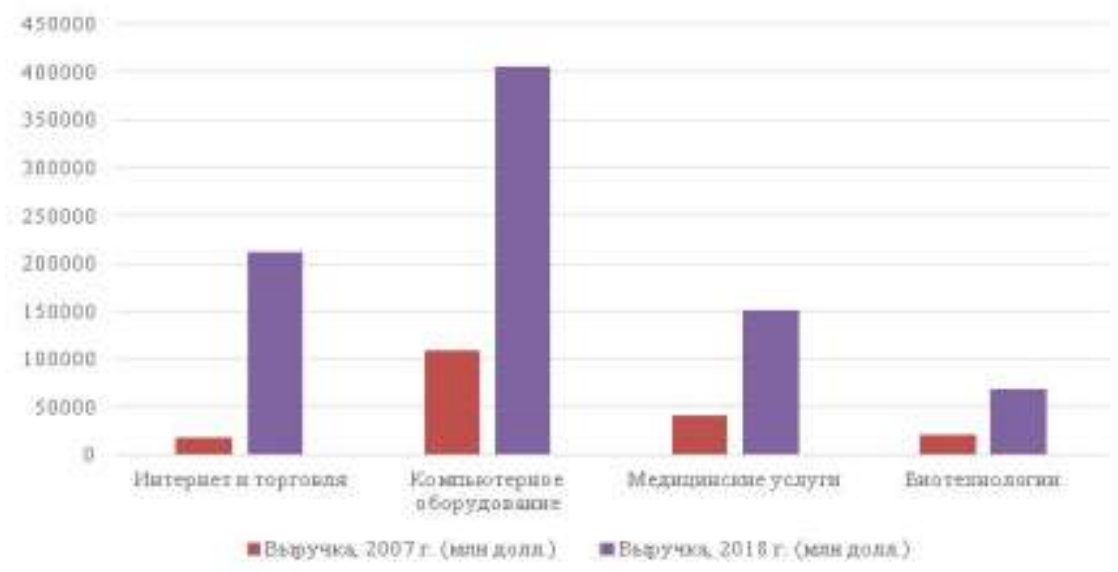

Puc. 3. Лидеры отраслевой динамики продаж крупнейших компаний за 2007-2018 гг., млн долл. США

Источник: составлено авторами по [29]

Колоссальный рост продаж в данных специализация объясняется огромным ростом за последние десять лет спросом на мобильную технику и программное обеспечение и всеобщей дигитализацией общества.

Происходит активный переход экономических субъектов от покупок в розничных магазинах к приобретениям в интернете. Крупнейший мировой интернет-магазин Amazon показал за последние 11 лет практически рекордное (более чем в 18 раз) увеличение объема продаж, что повлияло на другие традиционные сектора, отрасль розничной торговли бытовой техники пострадала от этого сильнее всего (рис. 4).

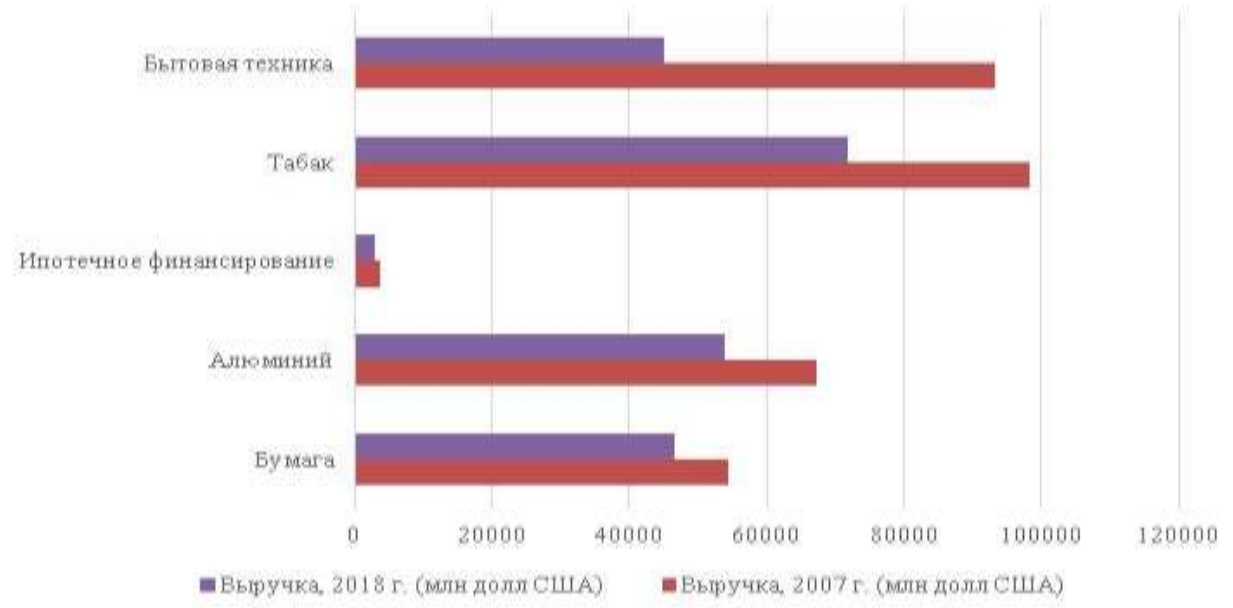

Puc. 4. Отрасли с наименьшей динамикой продаж за 2007-2018 гг., млн долл. США Источник: составлено авторами по [29] 
С появлением электронных книг и интернета, многие журналы и издательства перешли на online формат, что также отразилось на падении продаж бумажной отрасли, и, вполне возможно, в ближайшие десятилетия подобная цифровизация еще сильнее уменьшит данный сегмент.

Таким образом, технологические вызовы привели к необходимой адаптации к ним путем развития процессов дигитализации. Проявление дигитализации у компаний связано с вовлечением информационных технологий во все бизнес-процессы, не только начиная от закупок [30] до продаж с использованием цифровых платформ [31], технологий и рекламных кампаний, но и включая производственные процессы и НИОКР [32]. Как показывает мировая практика, крупнейшие компании наиболее активны во внедрении дигитализации, поэтому именно они были взяты в качестве объекта классификации.

\section{Модель классификации крупнейших компаний по лидерству и динамике прибыли}

Авторский подход к классификации крупнейших компаний осуществлялся по двум признакам, выделенных в рамках теории конкурентоспособности: 1) лидерство в отраслевой специализации рейтинга Global 2000, которое измерялось как доля компании в суммарном объеме продаж других компаний этой же специализации из рейтинга Global 2000; 2) рост финансовой результативности крупнейших компаний, оценивался через коэффициент роста прибыли компании за 11-тилетний период. Экономическое содержание первого признака позволяет, не ограничиваясь одной специализацией, ранжировать компании на группы в зависимости от их доли среди ближайших крупнейших конкурентов. За основу критериев распределения компаний по рыночной доле взята стратегия New Lanchester, развитая С. Бланком [33]:

- доля рынка > 75\%: «лидер-одиночка» (монополист) и «лидер дуополии»;

- доля рынка от 41 до 75\%: «стабильный лидер» на конкурентном рынке;

- доля рынка от 26 до 41\%: «неустойчивый лидер» на высококонкурентном рынке;

- доля рынка < 26\%: отсутствие явного лидера на открытом высококонкурентном рынке.

Второй признак рост финансовой результативности крупнейших компаний позволяет выявить такую экономическую составляющую как прибыльность компании за продолжительный период, которая позволяет выявить компании, применяющие более продуктивные стратегии развития, чем другие.

Исходя из выбранных признаков классификации, были выделены 4 следующие принципиально разные группы компаний (рис. 5).

\section{Материалы и методы исследования}

В качестве исходных данных были взяты рейтинги Forbes «Global 2000», включающие крупнейшие публичных компаниях мира за 2007-2018 гг., в том числе 25 российских компаний [29]. В качестве методов исследования применялся индикативный анализ финансовых и рыночных показателей крупнейших мировых компаний. Для построения классификации по первому признаку - лидерству крупнейших компаний рассчитывался показатель доля компании в отраслевой специализации рейтинга Forbes «Global 
2000». Согласно стратегии New Lanchester, если компания не обладает долей более $26 \%$, то она не осуществляет существенного воздействия на рынок [33]. Поэтому в качестве базового использовалось значения в $26 \%$ : разграничивающее рынки, где есть явный лидер и где нет компаний с долей более 1/4 рынка. Для построения классификации по второму признаку - росту финансовой результативности компаний было рассчитано медианное значение динамики прибыли крупнейших компаний из «Global 2000» за 2007-2018 гг. Поскольку в расчетах использовался продолжительный период (разность значений прибыли 2018 и 2007 гг.), то для вычисления реального, а не номинального роста прибыли и исключения из расчетов инфляционной составляющей, медианное значение было скорректировано на величину долларовой инфляции за данный период (21\% за период с 2007 по 2018 гг.), полученная величина была взята в качестве базового значения по второму признаку. С данными базовыми критериями авторы сравнивали значения каждой из 946 крупнейших компаний из «Global 2000»"

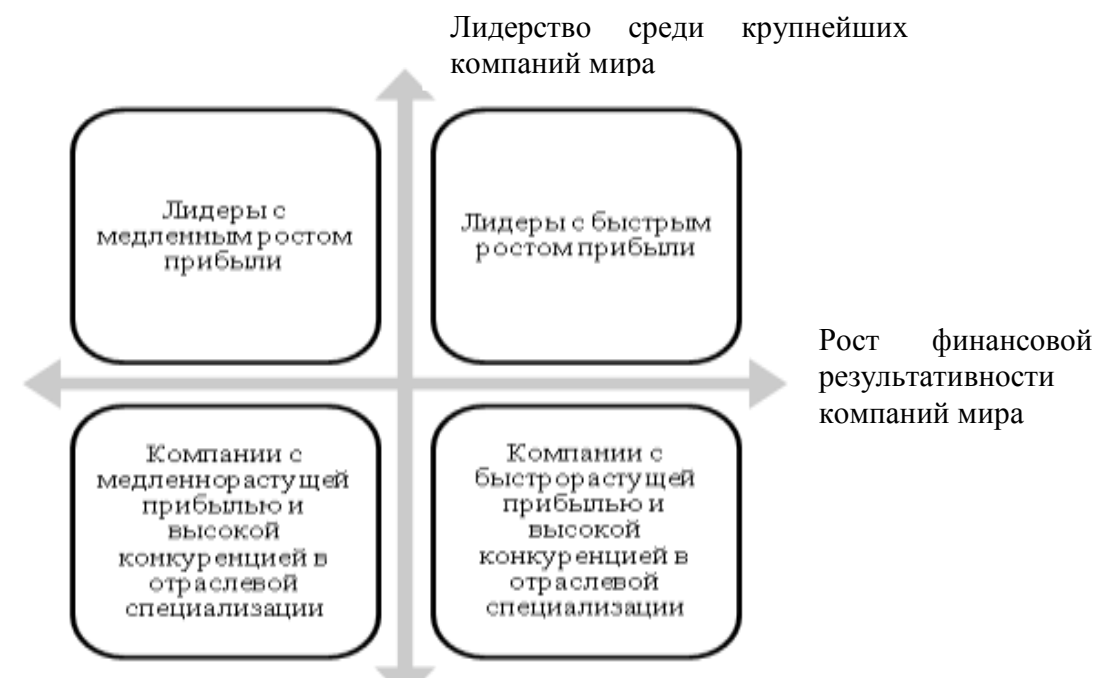

Puc. 5. Модель классификации крупнейших компаний по лидерству и динамике прибыли

Источник: составлено авторами

\section{Результаты исследования и их обсуждение}

В результате сравнения показателей каждой компании с базовыми значениями были получены четыре типа компаний с особыми характеристиками (конкурентоспособность, специализация, регион базирования) (рис. 6).

\footnotetext{
${ }^{1}$ Модель была построена по 946 компаниям, так как 1054 выбыли из рейтинга «Forbes 2000» за рассматриваемый 11-тилетний период.
} 


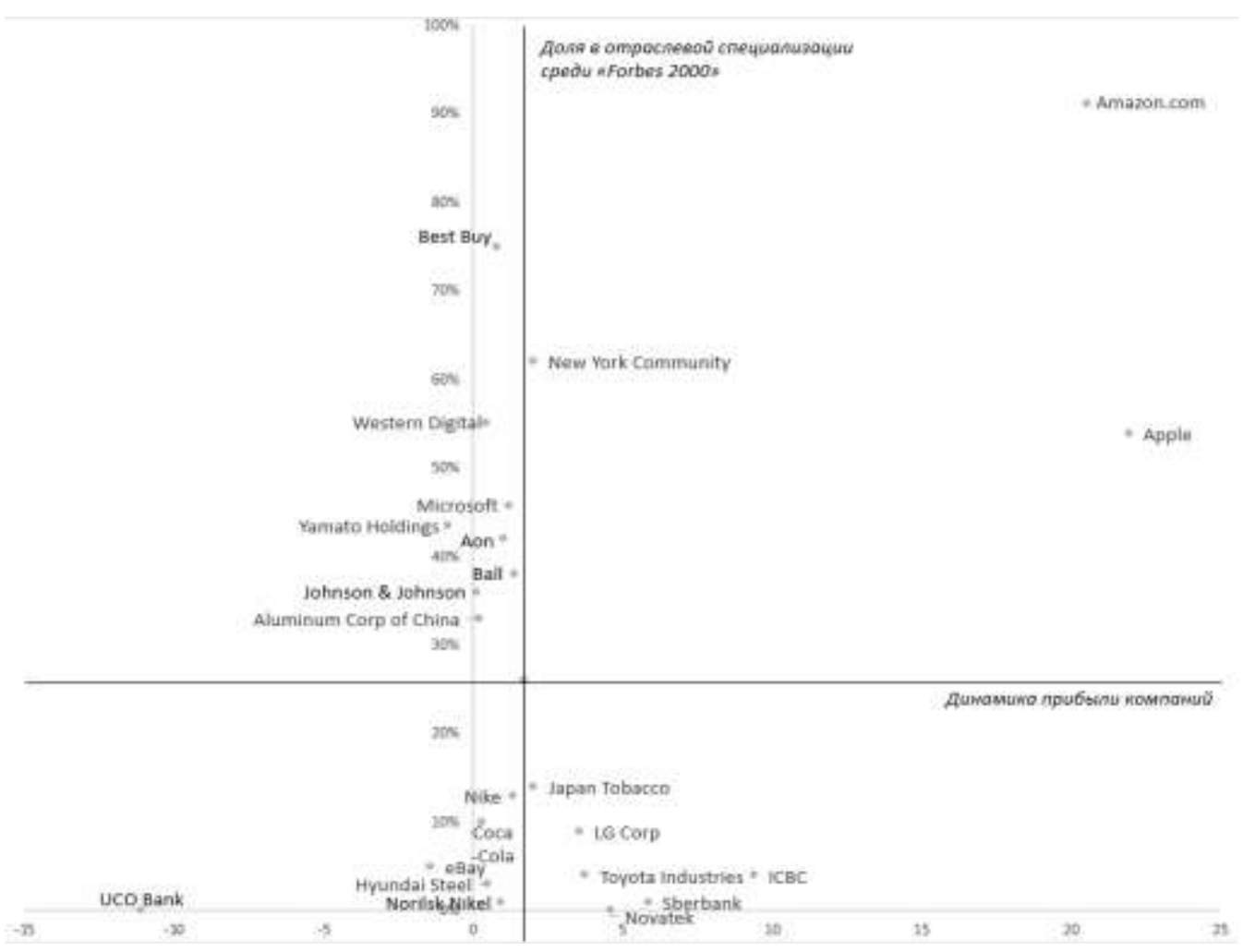

Puc. 6. Апробация модели: классификации крупнейших компаний ${ }^{2}$ по лидерству и Источник: рассчитано авторами по [29] динамике прибыли

1. Группа «крупнейшие компании-лидеры с быстрым ростом прибыли». Это компании монополисты (дуополисты) или лидеры отраслевой специализации, преимущественно IT сектора, в подавляющем большинстве из США. По первому показателю: «Amazon» обладает наибольшей доминирующей долей среди 946 крупнейших публичных компаний мира (89\%), то есть монополист среди крупнейших из «Global 2000». Одновременно с этим «Amazon» демонстрирует один из наибольших приростов прибыли - 20,5\%.

Представителем другой подгруппы «стабильные лидеры», включающей менее доминирующие в отраслевой специализации является «Apple» $(52 \%$ в отраслевом сегменте крупнейших компаний мира из «Global 2000») с наилучшим показателем динамики прибыли $(21,9 \%)$. Лидерство «Amazon» и «Apple» объясняется огромным ростом спроса общества на мобильность (онлайн покупки) и всеобщей дигитализацией (покупкой техники и программного обеспечения). Влияние дигитализации особенно заметно в сравнении с другой компанией, меньше использующей современные цифровые возможности - «New York Community» (фонды и ипотечное финансирование) представителем этой же подгруппы, но находящейся на периферии с показателя-

${ }^{2}$ На рисунке представлены примеры только некоторых крупнейших публичных компаний мира как типичного представителя сегмента классификации 
ми роста прибыли чуть больше среднего (2,02\%), но сохраняющего лидерскую долю (62\% от отраслевой специализации из «Global 2000»).

2. Группа «крупнейшие компании-лидеры с медленным ростом прибыли», т.е. данные компании представлены в отраслевой специализации, где у них практически нет конкурентов (монополисты, дуополисты). Но из-за умеренного спроса на продукцию имеют средне-низкие показатели динамики прибыли. Также их объединяет близкая отраслевая принадлежность (преимущественно технологический сектор) и регион базирования (преобладают развитые страны). Сильнее всего данная тенденция проявляется у Best Buy (розничная торговля компьютерами, электроникой) (доля 75\% от отраслевой специализации из «Global 2000») и Western Digital (компьютерные комплектующие для хранения данных) (доля 55\%), при минимальном росте динамики прибыли (0,79\% и 0,44\% соответственно). Например, компаний Microsoft представляет подгруппу - «стабильные лидеры» и занимает уже не настолько монопольное положение (46\% от отраслевой специализации из «Global 2000») как предыдущие компании, но обладает лучшим ростом прибыли $(1,19 \%)$.

3. Группа «крупнейшие компании с быстрорастущей прибылью и высокой конкуренцией в отраслевой специализации», т.е. данным компаниям достаточно сложно отвоевать себе большую рыночную долю из-за высокой конкуренции. В данной группе не прослеживается отчетливого влияния дигитализации на лидерство и прибыльность. Например, «LG Corp» (доля 9\% отраслевой специализации «Global 2000» и рост прибыли 3,56\%), «Toyota Industries» (доля 4\% и рост прибыли 3,75\%). В данную группу входят практически все российские крупнейшие публичные компании, например, «Сбербанк» обладает лучшим, чем предыдущие компании, показателем динамики прибыльности (5,85\%), но обладает меньшей рыночной долей $(1,0 \%$ от крупнейших банков, входящих в рейтинг). У «Новатека» чуть меньший рост $(4,58 \%)$ и доля в отраслевой специализации «Global 2000» существенно меньше 1\%.

4. Группа «крупнейшие компании с медленно растущей прибылью и высокой конкуренцией в отраслевой специализации». У данных компаний не получается достичь положительной реальной (с учетом инфляции) или номинальной динамики прибыли. Данная группа в основном представлена организациями, оказывающими банковские услуги, преимущественно в развивающихся странах, например, индийский «UCO Bank» (наибольший спад в динамике прибыли - 11,1\% при рыночной доле менее 1\%). Американский интернет-аукцион «еВау» является исключением из общей тенденции - использование дигитализации не приводит к улучшению лидерства и результативности (отрицательная динамика прибыли в -1,42\%). Компания «еВау» (доля в отраслевом сегменте рейтинга 5\%) также как, и «Coca-Cola» (доля 10\% и номинальный рост прибыли 0,28\%), и «Nike» (доля 13\% и номинальный рост прибыли $1,32 \%$ ) демонстрируют другую тенденцию - ухудшения показателей американских крупнейших компаний, не справившихся с конкуренцией. Единственной российской компанией в этой группе является «Норильский никель» с ростом прибыли всего 0,92\% и рыночной долей в «Global 2000»-1\%. 


\section{Выводы}

Апробация предлагаемой методики позволила выявить лидеров в отраслевой специализации. Регулярное применение методики позволит выявлять изменения, происходящие у текущих лидеров и заранее выявлять перспективные компании с быстрорастущей прибылью. Поэтому данная методика может использоваться как основа для принятия решений по развитию дигитализации различных отраслей и может быть значима при разработке и внедрении инструмента мониторинга и прогноза дигитализации лидирующих компаний.

Для определения предпосылок дигитализации и разграничения крупнейших публичных компаний мира на более однородные группы авторами была предпринята попытка их группировки исходя из динамичности их показателей. Изменение конкурентного положения компании проявляется в двух основных показателях, которые могут оценить результативность дигитализации как инструмента достижения цели международного лидерства. Первый характеризует динамику лидерства компании в отраслевой специализации через показатель темп роста оборота. Второй оценивает рост финансовой результативности компании через показатель темп роста прибыли.

Процессы дигитализации можно оценить по степени использования компаниями современных информационных технологий в бизнес-процессах. Так, по степени и активности внедрения процессов дигитализации, некоторые крупнейшие публичные компании мира по данным за период 2007-2018 годов могут быть отнесены к следующим группам:

1) «начинающие дигитализацию» - технологии, дополняющие отдельный элемент текущего бизнес-процесса; демонстрировали темп роста прибыли - в пределах 0-100\%, темп роста оборота - 150\%; они чаще всего представлены крупными компаниями, работающими в банковском секторе, нефтедобыче и связанной с ней сферами (например, нефте- и газодобывающие компании «Marathon Oil» (анализ больших данных скважин, беспилотные технологии) и «Hess» (машинное обучение, в программах бурения));

2) «расширяющие дигитализацию» - технологии, запускающие дополнительные бизнес-модели; компании этой группы показывают темп роста прибыли в районе 100-300\%, темп роста оборота - в пределах 150-300\%; в этой группе сосредоточены корпорации, работающие в сферах розничной торговли, металлургии, авиаперевозок (например, компании «Mitsui Fudosan» для укрепления своей корпорации в 2018 г. запустила венчурный инвестиционный проект, основанный на инновационных технологиях, реализующих концепцию «умный город»; «Nike» внедрило мобильное приложения Nike Fit, позволяющее индивидуально подобрать, купить и оформить доставку обуви, приложение Nike Run Club помогает выполнять физические упражнения; пассажиры компании «Southwest Airlines» во время полета могут смотреть телепередачи в прямом эфире, фильмы, обмениваться сообщениями);

3) «лидеры дигитализации» - технологии, принципиально изменяющие ключевые бизнес-процессы компаний; у них максимальные темпы роста прибыли - свыше 300\%, темп роста оборота - свыше 300\%; в этой группе сосредоточены компании, работающие в сферах электроники и IT индустрии (например, корпорации «NVIDIA» стала разрабатывать графические процессо- 
ры, в том числе для роботов, с использованием искусственного интеллекта и машинного обучения; «Mastercard» внедряет прямые анонимные блокчейнтранзакции; «Apple» создает свои продукты из новых материалов (алюминиевый сплав без примесей, олово в платах, сделанное из восстанавливаемых материалов), дополняет и заменяет функции микроплатежа, дисплей ультравысокой точности, сканер отпечатка пальцев и др.).

Как показывает пример выше представленных компаний, именно дигитализация выступает фактором конкурентоспособности и прибыли компаний второй и третьей группы, так как благодаря ей формируются, с одной стороны, дополнительные рынки и доходы на них, или за счет дополнительных (бизнес-модели создают новые источники монетизации), так и основных (передовые технологии) конкурентных преимуществ компании, с другой стороны, снижаются расходы в процессе внедрения этих технологий, влияние которых на финансовый результат пропорционально их весу в бизнес-процессе. Закономерно, что лидирующие позиции среди крупнейших мировых компаний занимают производители программного обеспечения, мобильной техники и другие высокотехнологические компаний, которые сумели использовать «окно возможностей» предоставляемых дигитализацией.

\section{Заключение}

Таким образом, проведенное исследование позволяет сделать следующие выводы.

Глобальные вызовы выступают важнейшим драйвером дигитализации экономики, порождают глобальную технологическую трансформацию и побуждают страны и бизнес искать открывающиеся возможности и нивелировать угрозы. Дигитализация, в свою очередь, выступает драйвером экономического развития. Авторская модель подтверждает, что крупнейшие публичные компании мира, стратегически осуществляющие дигитализацию своего бизнеса, являются или становятся рыночными лидерами с динамикой прибыли выше среднего.

Ведущие страны разработали и применяют стратегии технологического развития и трансформации бизнеса, стремясь использовать «окно возможностей», чтобы лидировать на рынках, в том числе на тех, которые еще появятся в среднесрочной и долгосрочной перспективе Возможности компаний противостоять глобальным вызовам напрямую зависит от их типа; в частности, выявлена особая роль крупнейших компаний в формировании и трансляции глобальных экономических тенденций в развитии процессов дигитализации.

В результате разработки и апробации авторской модели классификации крупнейших компаний по лидерству и динамике прибыли, получены четыре типа компаний, характеризующие конкурентоспособность, специализацию, регион базирования. Анализ крупнейших компаний мира за 11-летний период показал, что дигитализация влияет на их конкурентоспособность, они выбирают или вынуждены следовать одной из стратегий: начинать внедрять в отдельные элементы текущих бизнес-процессов; расширять дигитализацию, запускать дополнительные бизнес-модели или обеспечивать лидерство, используя дигитализацию в ключевых бизнес-процессах. 
Отечественным компаниям для того, чтобы не проиграть в конкурентной борьбе за стратегически важные для России рынки будущего, авторы рекомендуют в рамках стратегии НТИ разработать и внедрить инструменты регулярного мониторинга дигитализации лидирующих компаний и методику прогноза трансляции передовых элементов дигитализации. Особое внимание в создавшихся условиях следует уделить развитию процессов дигитализации в сфере медицинских услуг и биотехнологий, так как именно они во многом определяют лидирующие позиции компаний на мировом рынке.

\section{Список источников / References}

1. Цифровая экономика от теории к практике: как российский бизнес использует искусственный интеллект [Tsifrovaya ekonomika ot teorii $k$ praktike: kak rossiiskii biznes ispol'zuet iskusstvennyi intellekt [Digital economy from theory to practice: how Russian business uses artificial intelligence]]. Available at: https://raec.ru/activity/analytics/11002/ (accessed 23.04.2020).

2. Андреева Е.Л., Глухих П.Л., Мыслякова Ю.Г. Бизнес-стратегии участия компании в предпринимательских экосистемах. Управленец, 2018, т. 9, № 6, сс. 49-57. [Andreeva E.L., Glukhikh P.L., Mysljakova Ju.G. Biznes-strategii uchastija kompanii v predprinimatel'skih jekosistemah [Business strategies of company's participation in entrepreneurs' ecosystems]. Upravlenets = The Manager, 2018, vol. 9, no. 6. pp. 49-57.].

3. Орлов С. Мировой рынок мобильных приложений достиг \$76 млрд [Orlov S. Mirovoi rynok mobil'nykh prilozhenii dostig $\$ 76 \mathrm{mlrd}$ [The global market for mobile applications has reached $\$ 76$ billion]]. Available at: https://www.computerra.ru/233689/mirovoj-rynok-mobilnyh-prilozhenij-dostig-76$\mathrm{mlrd} /($ accessed 23.04.2020).

4. Березной А. Транснациональный бизнес в эпоху глобальной цифровой революции. Мировая экономика и международные отношении, 2018, № 9 (62), сс. 5-17. [Bereznoi A. Transnatsional'nyy biznes v epokhu global'noy tsifrovoy revolyutsii [Transnational business in the era of the global digital revolution]. Mirovaya ekonomika $i$ mezhdunarodnye otnosheniya = World Economy and International Relations, 2018, vol. 62, no. 9, pp. 5-17.].

5. Калаев Д. Почему хорошая компания - не всегда хорошая инвестиция. И наоборот [Kalaev D. Pochemu khoroshaya kompaniya - ne vsegda khoroshaya investitsiya. I naoborot [Kalayev D. Why a good company is not always a good investment? And vice versa]]. Available at: https://www.forbes.ru/tehnologii/348481-pochemu-horoshayakompaniya-ne-vsegda-horoshaya-investiciya-i-naoborot (accessed 23.04.2020).

6. Тойнби А.Дж. Постижение истории: Сборник / Перевод с английского Е. Д. Жаркова. Москва, Рольф, 2001. 640 с. [Tojnbi A. Dzh. Postizhenie istorii [Comprehension of history]. Moscow, Ajris Press, 2002. 640 p.].

7. Sandler T. Near horizons. In Global Challenges. An Approach to Environmental, Political, and Economic Problems. Cambridge, Cambridge University Press, 1997, pp. 199-214.

8. Bhargava V. Global issues for global citizens: an introduction to key development challenges. Washington: D.C. 2006. 490 p.

9. Gelsdorf K. Global Challenges and their Impact on International Humanitarian Action. Available https://www.unocha.org/sites/unocha/files/Global\%20challenges\%20and\%20their\%20i mpact\%20on\%20international\%20humanitarian\%20action.pdf (accessed 23.04.2020).

10. World Economic and Social Survey 2013, Sustainable Development Challenges. Available at: https://sustainabledevelopment.un.org/content/documents/2843WESS2013.pdf (accessed 23.04.2020). 
11. Sharp P., Leshner I. Meeting Global Challenges. Science, 2014, vol. 343, no. 6171. pp. 579-583.

12. Программа Открытого университета Сколково - Global Challenges [Programma Otkrytogo universiteta Skolkovo - Global Challenges [Skolkovo Open University Program - Global Challenges]]. Available at: http://sk.ru/opus/p/programglobalchallenges.aspx (accessed 23.04.2020).

13. The National Medium- and Long-Term Program for Science and Technology Development (2006-2020). Available at: https://www.itu.int/en/ITUD/Cybersecurity/Documents/National_Strategies_Repository/China_2006.pdf （accessed 23.04.2020).

14. Иванов С.А. Научно-техническая политика Китая: приоритеты догоняющего развития и результаты. Известия Восточного института, 2018, т. 38, № 2. сс. 6-23. doi: dx.doi.org/10.24866/2542-1611/2018-2/6-23. [Ivanov S.A. Nauchnotekhnicheskaya politika Kitaya: prioritety dogonyayushchego razvitiya i rezul'taty [China's science and technology policy: catching-up development priorities and results]. Izvestiya Vostochnogo instituta $=$ News of the Eastern Institute, 2018, vol. 38, no. 2, pp. 6-23. doi: dx.doi.org/10.24866/2542-1611/2018-2/6-23.].

15. Прогноз научно-технологического развития Российской Федерачии на период до 2030 года [Prognoz nauchno-tekhnologicheskogo razvitiya Rossiiskoi Federatsii na period do 2030 goda [Forecast of scientific and technological development of the Russian Federation for the period until 2030]]. Available at: http://static.government.ru/media/files/41d4b737638b91da2184.pdf Accessed 23.04.2020).

16. La stratégie nationale de recherché France - Europe 2020. Available at: Available at: https://cache.media.enseignementsup-

recherche.gouv.fr/file/Strategie_Recherche/26/9/strategie_nationale_recherche_397269.pdf (accessed 23.04.2020).

17. Краснова Г.А., Ницевич В.Ф., Тагирова Ш.В. Национальная стратегия научных исследований Франции. Ученые записки ОГУ. Серия: Гуманитарные и сочиальные науки, 2015, №5, сc. 351-357. [Krasnova G.A., Nicevich V.F., Tagirova SH.V. Nacional'naja strategija nauchnyh issledovanij Francii [French National Research Strategy]. Uchenye zapiski OGU. Seriya: Gumanitarnye $i$ sotsial'nye nauki = Scientific journal "Scientific notes of Orel state university": Series: Humanities and social Sciences, 2015, no. 5, pp. 351-357.].

18. A strategy for American innovation. Available at: https://obamawhitehouse.archives.gov/sites/default/files/strategy_for_american_innovat ion_october_2015.pdf (accessed 23.04.2020).

19. Vision 2025 Korea's long-term for Science and Technology Development. Available at: http://unpan1.un.org/intradoc/groups/public/documents/APCITY/UNPAN008040.pdf (accessed 23.04.2020).

20. Science and Technology Basic Plan. Available at: https://www8.cao.go.jp/cstp/kihonkeikaku/5honbun.pdf (accessed 23.04.2020).

21. Швыдко В.Г. Новый пятилетний план научно-технического развития Японии: смена акцентов в государственной политике стимулирования науки и инноваций. Международный научно-исследовательский журнал, 2016, т. 53, № 11, сc. 77-80. [Shvydko V.G. Novyj pjatiletnij plan nauchno-tehnicheskogo razvitija Japonii: smena akcentov v gosudarstvennoj politike stimulirovanija nauki i innovacij [The new five-year plan of scientific and technological development of Japan: a change of emphasis in government policy to stimulate science and innovation]. Mezhdunarodnyy nauchno-issledovatel'skiy zhurnal $=$ International research journal, 2016, vol. 53, no. 11, pp. 77-80.]. 
22. Портер М. Международная конкуренция: конкурентные преимущества стран. Москва, Международные отношения, 1993. 896 с. [Porter M. Mezhdunarodnaja konkurencija: konkurentnye preimushhestva stran [International competition: Competitive advantages of countries]. Moscow, Mezhdunarodnye otnosheniya, 1993. 896 p.].

23. Кузнецова Н.П., Лещенко К.Е., Ломагин Н.А. Экономическая теория и хозяйственная практика: глобальные вызовы. Вестник Санкт-Петербургского университета. Экономика, 2012, № 2, сс. 162-168. [Kuznetsova N.P., Leshchenko K.E., Lomagin N.A. Jekonomicheskaja teorija i hozjajstvennaja praktika: global'nye vyzovy [Economic theory and economic practice: global challenges]. Vestnik SanktPeterburgskogo universiteta. Ekonomika $=S t$ Petersburg University Journal of EconomicStudies, 2012, no. 2. pp. 162-168.].

24. Стецюкевич А.С. Развитие интегрированных корпоративных структур в промышленности - глобальный вызов традиционной методологии стратегического управления. Инновации и инвестиции, 2016, № 3, сc. 72-77. [Stetsyukevich A.S. Razvitie integrirovannyh korporativnyh struktur $\mathrm{v}$ promyshlennosti - global'nyj vyzov tradicionnoj metodologii strategicheskogo upravlenija [Development of integrated corporate structures in industry - a global challenge to the traditional methodology of strategic management]. Innovatsii $i$ investitsii = Innovations and investments, 2016, no. 3. pp. 72-77.].

25. Park H.S. Technology convergence, open innovation, and dynamic economy. Journal of Open Innovation: Technology, Market, and Complexity, 2017, vol. 24, no. 3, pp. 1-19.

26. Zhang T. Global economic challenges and opportunities. Business Economics, 2018, vol. 53, no. 1, pp. 3-9.

27. Hoontrakul P. Economic Transformation and Business Opportunities in Asia. Bangkok, Palgrave Macmillan, 2018. 369 p.

28. Окунев В.И. Усиление глобальной конкуренции как долгосрочный системный вызов. Международная экономика, 2019, № 2, сс. 68-76. [Okunev V.I. Usilenie global'noi konkurentsii kak dolgosrochnyi sistemnyi vyzov [Strengthening global competition as a long-term systemic challenge]. Mezhdunarodnaya ekonomika $=$ The world economics, 2019, no. 2, pp. 68-76.].

29. Forbes «Global 2000». Available at: https://www.forbes.com/global2000/list/ (accessed: 23.04.2020).

30. Авдеева И.Л., Полянин А.В., Головина Т.А. Цифровизация промышленных экономических систем: проблемы и последствия современных технологий. Изв. Сaрат. ун-та. Нов. сер. Сер. Экономика. Управление. Право, 2019, Т. 19, №3. cc. 238-245. DOI: https://doi.org/10.18500/1994-2540-2019-19-3-238-245. [Avdeeva I. L., Polyanin A. V., Golovina T. A. Tsifrovizatsiya promyshlennykh ekonomicheskikh sistem: problemy i posledstviya sovremennykh tekhnologii [Industrial Economic Systems' Digitalization: Problems and Consequences of Modern Technologies]. Izvestiya Saratovskogo universiteta. Novaya seriya. Seriya «Ekonomika. Upravlenie. Pravo = Izvestiya of Saratov university. New series. series: economics. Management. Law, 2019, vol. 19, no. 3, pp. 238-245. DOI: https://doi.org/10.18500/1994-2540-2019-19-3-238-245].

31. Володин В.М., Надькина Н.А. Формирование инновационной инфраструктуры цифровизации производства на предприятиях промышленности и АПК. Известия высших учебных заведений. Поволжский регион. Экономические науки, 2018, №2 (8), cc. 3-12. DOI 10.21685/2309-2874-2018-2-1 [Volodin V. M., Nad'kina N. A. Izvestiya vysshikh uchebnykh zavedenii. Povolzhskii region. Ekonomicheskie nauki [The formation of innovation infrastructure of digitalization of production at industrial and agricultural enterprises]. Izvestiya vysshikh uchebnykh zavedenii. Povolzhskii re- 
gion. Ekonomicheskie nauki = University proceedings. Volga region. Economic sciences, 2018, no. 2 (8), pp. 3-12. DOI 10.21685/2309-2874-2018-2-1.].

32. Аптекман А., Калабин В., Клинцов В. и др. Цифровая Россия: новая реальность. McKinsey, 2017. 133 c. [Aptekman A., Kalabin V., Klintsov V. i dr. Tsifrovaya Rossiya: novaya real'nost' [Digital Russia: a new reality]]. McKinsey, 2017. 133 p. Available at: https://www.forbes.com/global2000/list/ (accessed: 25.06.2020).

33. Blank S. G. The Four Steps to the Epiphany. Cafepress. 2005. 276 p.

\section{Сведения об авторах / About authors}

Андреева Елена Леонидовна, доктор экономических наук, профессор, руководитель центра региональных компаративных исследований, Институт экономики Уральского отделения РАН. 620014 Россия, г. Екатеринбург, ул. Московская, д. 29. ORCID ID: 0000-0003-4975-0905.

E-mail:elenandr@mail.ru

Elena L. Andreeva, Doctor of Economic Sciences, Professor, Head of the Centre of Regional Comparative Research, Institute of Economics at the Ural Branch of the Russian Academy of Sciences. 29 Moskovskaya str., Yekaterinburg, Russia 620014. ORCID ID: 0000-0003-4975-0905.E-mail: elenandr@mail.ru

Глухих Павел Леонидович, кандидат экономических наук, доцент, старший научный сотрудник центра региональных компаративных исследований, Институт экономики Уральского отделения РАН. 620014 Россия, г. Екатеринбург, ул. Московская, д. 29.

ORCID ID: 0000-0001-5992-3780. E-mail: Gluchih_P_L@mail.ru

Pavel L. Glukhikh, Candidate of Economic Sciences, Associate Professor, Research Fellow Centre of Regional Comparative Research, Institute of Economics at the Ural Branch of the Russian Academy of Sciences. 29 Moskovskaya str., Yekaterinburg, Russia 620014. ORCID ID: 0000-0001-5992-3780. E-mail: Gluchih_P_L@mail.ru

Красных Сергей Сергеевич, младший научный сотрудник лаборатории моделирования пространственного развития территории, Институт экономики Уральского отделения РАН. 620014 Россия, г. Екатеринбург, ул. Московская, д. 29. ORCID ID: 0000-0002-2692-5656.

E-mail: sergeykrasnykh@yahoo.com

Sergey S. Krasnykh, Junior Researcher of the Laboratory of Modelling the Spatial Development of the Territories, Institute of Economics at the Ural Branch of the Russian Academy of Sciences. 29 Moskovskaya str., Yekaterinburg, Russia 620014. ORCID ID: 0000-0002-2692-5656.

E-mail: sergeykrasnykh@yahoo.com 